\section{Espacialização da precipitação na escala mensal e diária em uma microbacia localizada no Vale do Paraíba do Sul, São \\ Paulo}

Resumo: 0 presente estudo foi realizado com o intuito de avaliar a interpolação da precipitação pelo método da Krigagem na escala mensal e diária em uma microbacia localizada no Vale do Paraiba do Sul. A precipitação observada foi coletada por um pluviômetro localizado na microbacia do Ribeirão dos Macacos. A precipitação interpolada foi obtida por Plataformas de Coleta de Dados próximas a microbacia deste estudo. Quando se faz a interpolação da precipitação na escala diária há uma queda no coeficiente de determinação de $54,3 \%$ quando comparado à interpolação feita na escala mensal. Assim, ao se utilizar a técnica da Krigagem, pode-se obter a precipitação na escala mensal $\left(R^{2}=92,2 \%\right)$ com maior segurança quando comparado à escala diária $\left(\mathrm{R}^{2}=37,9 \%\right)$.

\section{Spatialization rainfall in monthly and daily scale in a watershed located in South Valley Paraíba, São Paulo}

\begin{abstract}
This study was conducted in order to evaluate the interpolation method of rainfall by kriging method in monthly and daily scale in a watershed located in South Valley Paraiba. The observed rainfall was collected by a rain gauge located in the watershed of the Apes. The interpolated rainfall was obtained by Data Collection Platforms near the watershed study. When does the interpolation of rainfall in the daily scale there is a drop in the coefficient of determination of $54.3 \%$ when compared to the interpolation done on a monthly scale. Thus, when using the Kriging technique, one can obtain the rainfall monthly scale $\left(R^{2}=92.2 \%\right)$ more safely compared to the daily scale $\left(R^{2}=37.9 \%\right)$.
\end{abstract}

Livia Alves Alvarenga*

Maria Paulete Pereira Martins*

Luz Adriana Cuartas*

Denilson Ribeiro Viana*

Alexandra Andrade*

*Instituto Nacional de Pesquisas Espaciais

${ }^{\star *}$ Instituto Oikos deAgroecologia

Palavras-chave: Microbacia; Interpolação e Precipitação.

Key-Words: Watershed; Interpolation and Rainfall. 


\section{Introdução}

Devido à variação dos elementos climáticos, as diferentes atividades em uma determinada área estão expostas a riscos e insucessos. A variabilidade do elemento climático precipitação, apresenta grande relevância em uma microbacia, sendo o seu acompanhamento imprescindível para o planejamento agrícola e ambiental, especialmente para o correto dimensionamento de obras hidráulicas, tanto na construção civil quanto na conservação do solo e água.

A região do Vale do Paraíba do Sul- São Paulo é uma das mais populosas e industrialiadas do país, sendo assim, muito importante num contexto social e econômico. Desta maneira, torna-se necessário salientar que as alterações nas propriedades físicas da superfície podem modificar o ciclo da água e fluxos de energia (radiação solar, troca de calor) que podem ter impactos significativos no clima em escala local e regional. É possível que as mudanças no clima alterem a temperatura, a precipitação, e aumentem a variabilidade dos eventos de precipitação (DUFEK e AMBRIZZI, 2008).

Um dos principais ramos de pesquisa em geografia, hidrologia e climatologia consiste, atualmente, na geração de mapas de precipitação para subsidiar a implantação de projetos agrícolas e ambientais, por meio da análise de técnicas de interpolação espacial, reconstituindo a distribuição espacial da precipitação. Devido às dificuldades em se obter a precipitação em locais desprovidos de dados, pode-se trabalhar com procedimentos estatísticos para interpolação dos dados existentes, com base em diferentes instrumentos (pluviômetro, Plataforma de Coleta de dados) vizinhos ao local onde se precisa obter a distribuição da precipitação. Dentre as técnicas estatísticas usadas para análise e interpretação de dados climáticos, encontra-se a Geoestatística, que tem como característica principal a análise da distribuição espacial e/ou temporal entre as observações (CAMARGO et al. 2004).

O método de interpolação de dados Krigagem foi desenvolvido para solucionar problemas de mapeamentos geológicos, mas seu uso também se expandiu com sucesso no mapeamento pedológico (Menezes et al. 2009), hidrológico (Danfa et al. 2011), atmosférico (Viana, 2009) entre outros.

A estrutura teórica da Krigagem é baseada no conceito de variável regionalizada, que é uma variável distribuída no espaço (ou tempo), cujos valores são considerados como realizações de uma função aleatória. Esta permite incluir hipóteses estatísticas em processos espaciais locais. A variação espacial de uma variável regionalizada pode ser expressa pela soma de três componentes: a) uma componente estrutural, associada a um valor médio constante ou a uma tendência constante; b) uma componente aleatória, espacialmente correlacionada; e c) um ruído aleatório ou erro residual. Se o vetor $\mathrm{x}$ representa uma posição em uma, duas ou três dimensões, então o valor da função aleatória $Z$, em x, é dada por (detalhes em CAMARGO et al. 2004):

$$
Z(x)=\mu(x)+\varepsilon^{\prime}(x)+\varepsilon^{\prime \prime}
$$

em que:

$\mu(x)$ : é uma função determinística que descreve a componente estrutural de $Z$ em $x ; \varepsilon^{\prime}(x)$ : é um termo estocástico correlacionado, que varia localmente;

$\varepsilon^{\prime \prime}:$ é um ruído aleatório não correlacionado, com distribuição normal, com média zero e variância $\sigma^{2}$.

Segundo Barbosa (2006), para propor uma análise regional dos elementos climáticos em uma

Geografia Ensino \& Pesquisa, v. 16, n.3 p. 179-188, set./dez. 2012

Espacialização da precipitação na escala mensal e diária em uma microbacia localizada no Vale do Paraíba do Sul, São Paulo região torna-se necessário distribuir esses elementos espacialmente, de modo que as regiões climáticas sejam mapeadas. $O$ autor em seu trabalho utilizou dados de precipitação (mensais e anuais) e temperatura (médias mensais e anuais) de várias localidades no estado de São Paulo, cobrindo um período de 30 anos. A partir desses dados, foram elaborados climogramas e uma série de mapas, utilizando a técnica da Krigagem, evidenciando que o estado de São Paulo apresenta tipos climáticos distintos.

Mello et al. (2003) objetivaram comparar os dois procedimentos estatísticos mais exatos, que são a Krigagem (interpolador geoestatístico) e o inverso do quadrado da distância para interpolação 
dos parâmetros da equação de chuvas intensas. Foram utilizadas 140 estações meteorológicas do estado de São Paulo, as quais dispõem da respectiva equação de chuvas intensas, estimada com base em dados pluviométricos. Constatou-se que ambos os métodos utilizados apresentaram boa precisão, mas a Krigagem produziu menores erros médios para 11 estações, verificando-se melhorias consideráveis em especial para tempos de retorno e tempos de duração da precipitação usuais em projetos em pequenas bacias hidrográficas. Assim, foi sugerido este método como o mais adequado.

Outros autores como Carvalho e Assad (2005), por meio da comparação de interpoladores univariados usados na obtenção da distribuição espacial da precipitação pluvial média anual para o Estado de São Paulo, mostraram que o interpolador geoestatístico de Krigagem ordinária, apresenta melhor resultado que os interpoladores Inverso do Quadrado da Distância e Curvatura Mínima (estes ignoram a dependência espacial entre observações). Este estudo enfatizou que a diferença entre os valores observados e estimados, utilizando o método da Krigagem, foi muito menor do que para os outros dois métodos utilizados. Desta forma, a Krigagem foi o melhor interpolador utilizado, sendo assim, indicado para ser usado na distribuição espacial de precipitação pluvial média anual.

Propõe-se com este estudo, obter e analisar a distribuição da precipitação na escala mensal e diária (utilizando a Krigagem) na microbacia do Ribeirão dos Macacos (Vale do Paraíba-SP), por meio de Plataformas de Coleta de Dados-PCD's, e assim, com um pluviômetro localizado na microbacia, avaliar os dados de precipitação interpolados.

\section{Material e Métodos}

A microbacia onde foi realizado este estudo é denominada Ribeirão dos Macacos, um afluente do rio Paraíba do Sul, no estado de São Paulo, região sudeste do Brasil., A área da microbacia compreende aproximadamente $39 \mathrm{~km}^{2}$, o equivalente a 3900 hectares, que estão localizados entre as coordenadas de $22^{\circ} 38^{\prime} 56,2^{\prime \prime} \mathrm{S}, 45^{\circ} 15,2^{\prime} 2,6^{\prime \prime} \mathrm{W}$ e $22^{\circ} 42^{\prime} 45,1^{\prime \prime} \mathrm{S}, 4^{\circ} 6^{\prime} 59,6^{\prime \prime} \mathrm{W}$, como se observa na Figura 1 (retângulo superior e inferior direito).

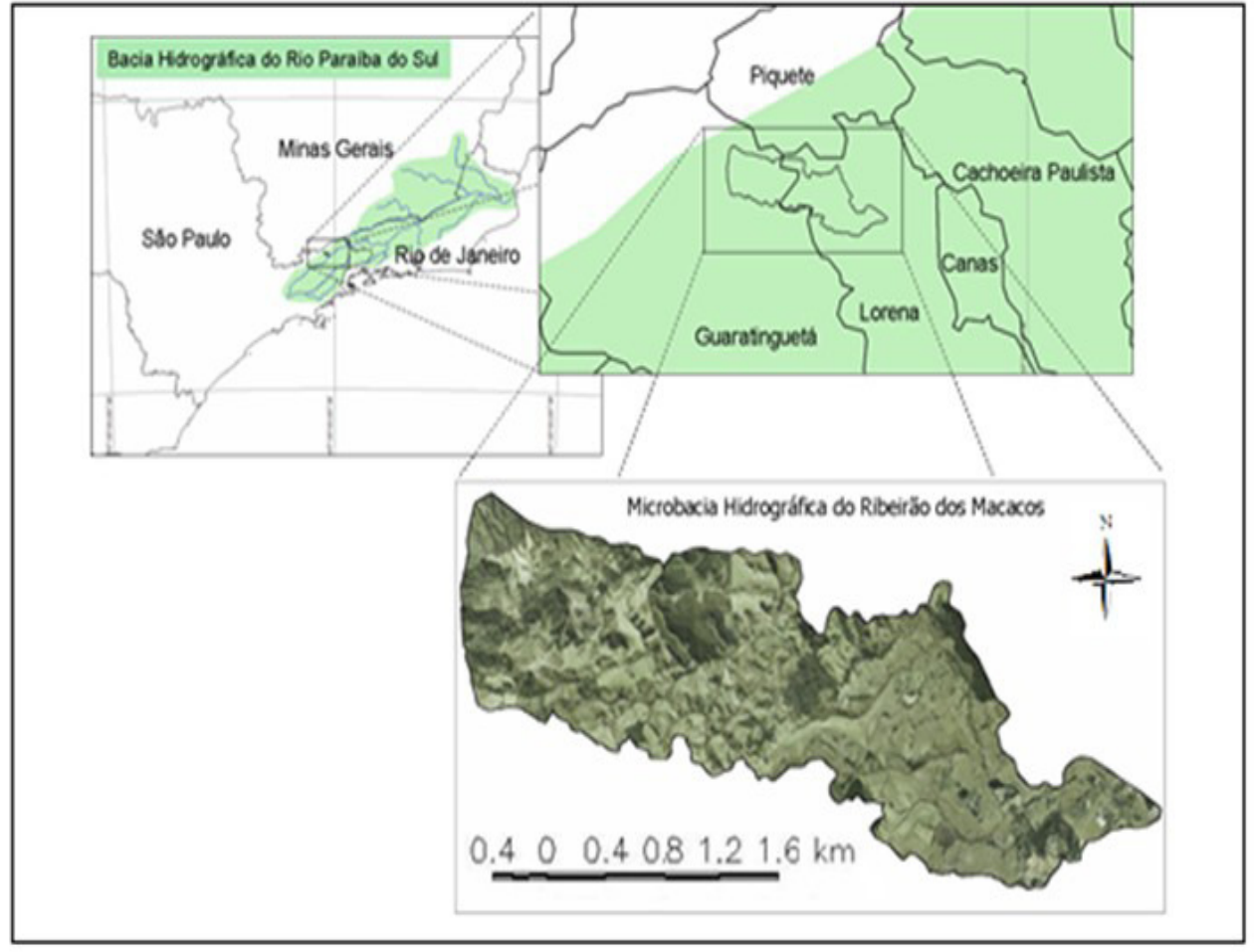

Figura 1- Localização da microbacia do Ribeirão dos Macacos-SP. Fonte: Instituto Oikos de Agroecologia [ca. 2009].
Geografia Ensino \& Pesquisa, v. 16, n. 3 p. 179-188, set./dez. 2012

Alvarenga, L. A.; Martins, M. P. P.; Cuartas, L. A.; Viana, D. R. Andrade, $A$. 
O Ribeirão dos Macacos nasce no município de Guaratinguetá e adentra em Lorena pelo noroeste, a aproximadamente dois quilômetros da divisa dos municípios de Lorena e Piquete. Suas principais nascentes localizam-se em cotas próximas dos $1100 \mathrm{~m}$, nos contrafortes da Serra da Mantiqueira, no município de Guaratinguetá. No seu percurso total de 19,12 km (Figura 2), apresenta um desnível médio de $27,7 \mathrm{~m} / \mathrm{km}$, com os maiores desníveis no município de Guaratinguetá, onde se localiza aproximadamente $40 \%$ da microbacia. O Ribeirão dos Macacos deságua no rio Paraíba do Sul, nas proximidades da Rodovia Federal BR 459, que liga Lorena a Itajubá em Minas Gerais, na cota aproximada de $520 \mathrm{~m}$.

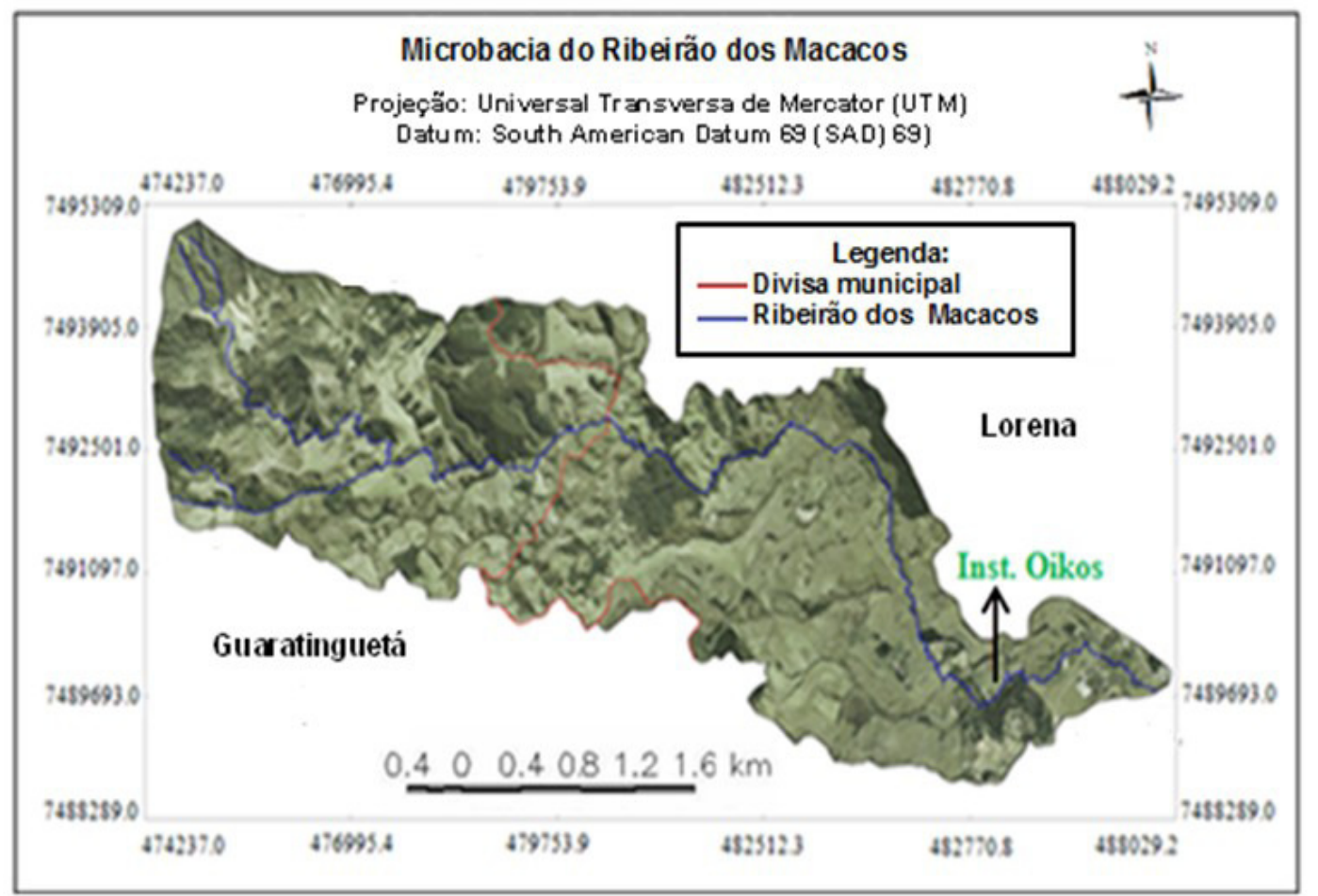

Figura 2- Mapa hidrográfico da microbacia do Ribeirão dos Macacos.

Fonte: Instituto Oikos de Agroecologia [ca. 2009].

De acordo com Fisch (1995) o clima da região apresenta temperaturas elevadas, com média anual de $22^{\circ} \mathrm{C}$ e duas estações de precipitação definidas: uma chuvosa que corresponde ao verão, e outra seca, que corresponde ao inverno. Na estação chuvosa (verão) a Zona de Convergência do Atlântico Sul (ZCAS) é um dos principais mecanismo responsável pelo aumento da precipitação (LIMA et al., 2010).

Por meio dos dados das Plataformas de Coleta de Dados-PCD's (CPTEC/INPE), localizadas no Vale do Paraíba, foi possível espacializar a precipitação (mensal e diária) e obter a precipitação em determinada localidade da microbacia do Ribeirão dos Macacos.

Para interpolação da precipitação por meio da técnica da Krigagem (linear) é utilizado o software Surfer 8.0 ๑, o qual gera mapas de distribuição espacial da precipitação (GOLDEN SOFTWARE, 2002). Na Figura 3, encontra-se a localização das Plataformas de Coleta de Dados (PCD's) na região de estudo.

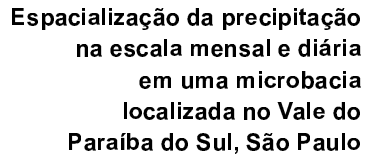




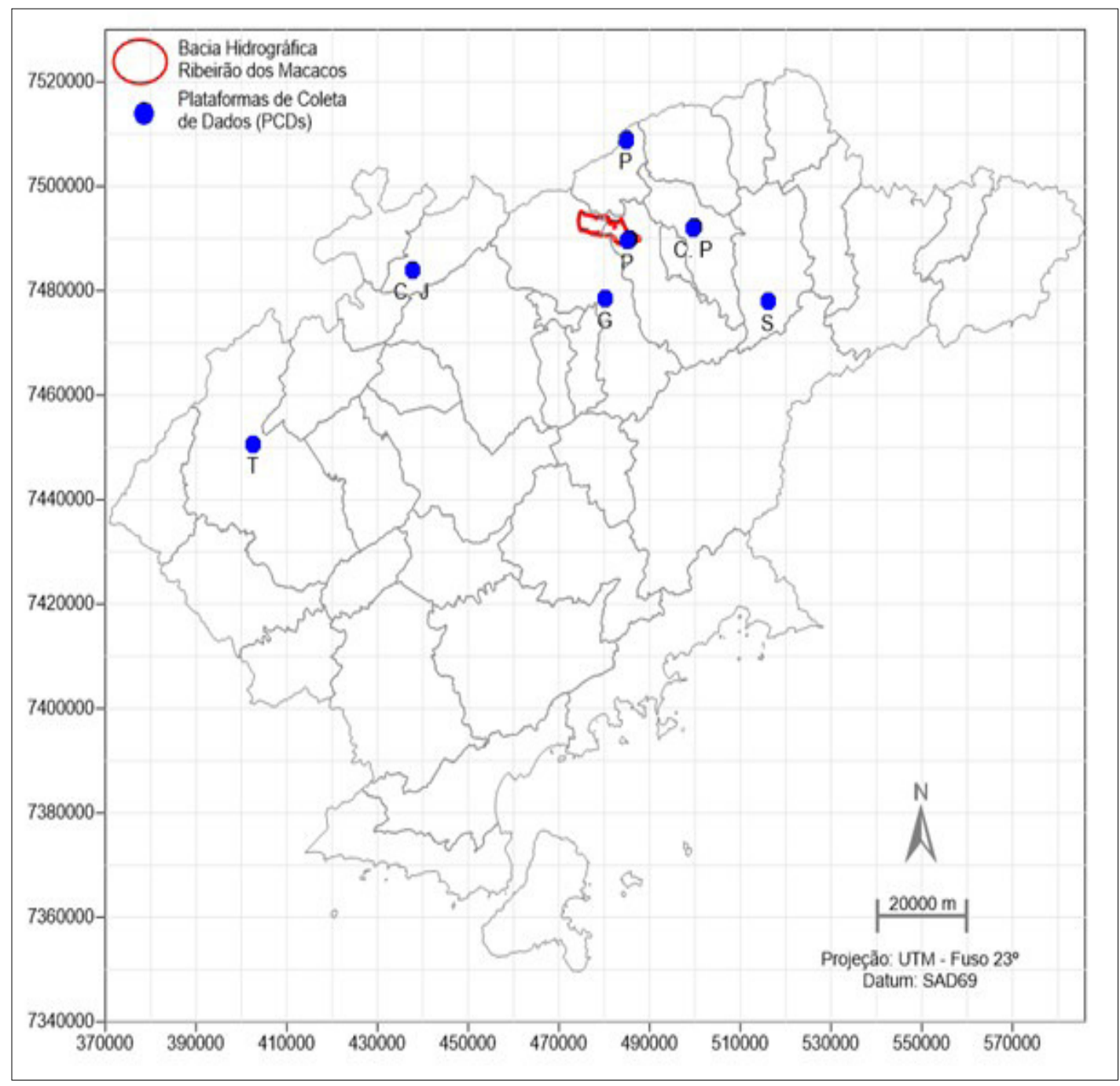

Figura 3- Mapa com a localização das PCD's (T: Taubaté; C.J: Campos do Jordão; G: Guaratinguetá; S: Silveiras; C.P: Cachoeira Paulista; P: Piquete) próximo a região da Microbacia do Ribeirão dos Macacos (na microbacia P: pluviômetro).

As PCD's utilizadas neste estudo estão instaladas em torres de 10 metros e, os dados gerados são transmitidos via satélite. Assim por meio dos satélites é estabelecida a comunicação entre as plataformas e as estações de recepção. Os dados das PCD's são coletados e armazenados por um "datalogger", sendo obtido o registro dos dados a intervalos, da ordem de minutos ou até segundos, dependendo da duração e intensidade da precipitação. Também são medidos outros dados horários como: Temperatura do ar $\left({ }^{\circ} \mathrm{C}\right)$, umidade relativa do ar $(\%)$, velocidade do vento $\left(\mathrm{m} \mathrm{s}^{-1}\right)$, radiação solar ( $\mathrm{w} \mathrm{m}^{-2}$ ) e pressão atmosférica $(\mathrm{mb})$.

Para validação dos dados de precipitação interpolada, foi utilizado um pluviômetro (fabricante COMIND) localizado nas coordenadas de $22^{\circ} 42^{\prime} 5,4^{\prime \prime} \mathrm{S}, 45^{\circ} 08^{\prime} 38,5^{\prime \prime} \mathrm{W}$, instalado na microbacia do Ribeirão dos Macacos, na sede do Instituto Oikos de Agroecologia (O Instituto Oikos de Agroecologia é uma instituição privada que desenvolve ações de restauração ambiental, adequação de métodos produtivos, conservação dos recursos naturais, mobilização e capacitação de produtores rurais na região deste estudo).

A interpolação mensal e diária dos dados de precipitação foi feita para o período de Junho/2010 até julho/2011 toda vez que alguma das PCD's ou pluviômetro local apresentou valor igual ou superior a $1 \mathrm{~mm}$ precipitado. Este limiar também foi adotado por Dereczynski et al. (2009) no estudo da climatologia da precipitação no município do Rio de Janeiro.

Todos os dados relacionados (interpolados e observados) se encontram na mesma localização geográfica (coordenadas de $22^{\circ} 42^{\prime} 5,4^{\prime \prime} \mathrm{S}, 45^{\circ} 08^{\prime} 38,5^{\prime \prime} \mathrm{W}$ ). Desta forma, obteve-se a análise de

Geografia Ensino \& Pesquisa, v. 16, n.3 p. 179-188, set./dez. 2012

Alvarenga, L. A.; Martins, M. P. P.; Cuartas, L. A.; Viana, D. R. Andrade, $A$. 
variância (valor do teste F) da regressão linear dos valores de precipitação observada (dados do pluviômetro localizado na sede Instituto Oikos de Agroecologia) em relação aos valores de precipitação mensal e diária interpolada (dados das PCD's localizadas no Vale do Paraíba) separadamente. Desta maneira é possível observar significância em cada um dos modelos de regressão linear obtidos quando o valor $F_{c}\left(F\right.$ calculado) for maior que o $F_{t}(F$ tabelado) (COSENTINO, 1977). Assim, é possível validar a técnica da interpolação da precipitação utilizando o método da Krigagem e recomendar ou não 0 uso desta técnica em outros estudos de espacialização da precipitação.

\section{Resultados e Discussões}

Como se pode observar na Figura 4 os dados de precipitação mensal das PCD's (Cachoeira Paulista, Campos do Jordão, Garatinguetá, Piquete, Silveiras e Taubaté), localizadas no Vale do Paraíba do Sul-SP (próximas à região de estudo), mostraram que as maiores precipitações aconteceram na PCD localizada em Piquete. Está é a única PCD localizada acima da cabeceira da microbacia de estudo com uma altitude de 1144 m (Figura 3).

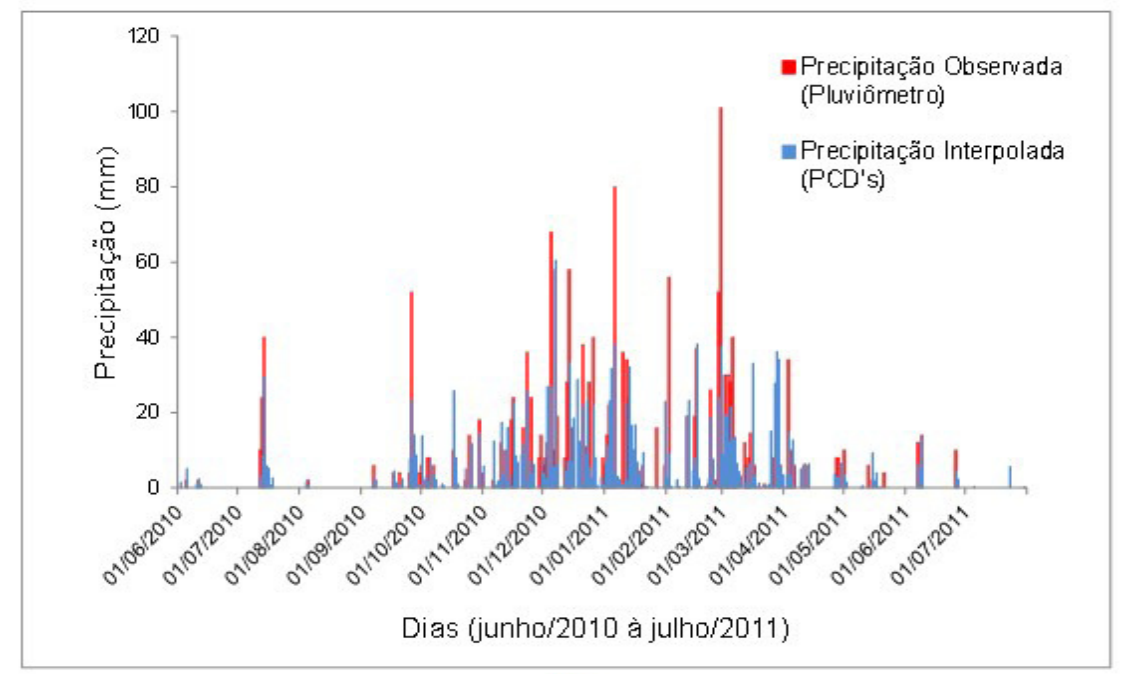

(b)

Figura 4- Precipitação mensal do pluviômetro localizado na microbacia (Instituto Oikos de Agroecologia) e das PCD's próximas da região de estudo, no período de junho/2010 até julho/2011.

Assim, pode-se dizer que na maioria das vezes a distribuição da precipitação mensal na região (utilizando a interpolação) aconteceu das maiores altitudes para as menores altitudes, ou seja, da montante para a jusante da microbacia. Este padrão de distribuição espacial da precipitação pode ser explicado pelo deslocamento preferencial dos sistemas meteorológicos produzindo máximos (mínimos) de precipitação à barlavento (sotavento) das serras (DERECZNSKI et al. 2009). Santos et al., (2007), também enfatizaram que as diferenças de altitude dentro da bacia influenciam diretamente na forma com que a precipitação acontece. Desta maneira, estas diferenças poderão ser úteis para um bom planejamento ou manejo de bacias, devido ao fato de se poder acompanhar

Geografia Ensino \& Pesquisa, v. 16, n.3 p. 179-188, set./dez. 2012

Espacialização da precipitação na escala mensal e diária em uma microbacia localizada no Vale do Paraíba do Sul, São Paulo a distribuição de precipitações intensas e vazão nos corpos d'água junto às diferenças de altitudes em diferentes localidades.

Na Figura 5 (a) apresenta-se a precipitação mensal interpolada e observada, das PCD's e do pluviômetro, ambos para a mesma localização geográfica. Pode-se observar que na maioria dos meses a precipitação interpolada (utilizando a técnica da Krigagem) foi subestimada, exceto nos meses de junho/2010, outubro/2010, janeiro/2011, março/2011 e julho/2011. Isso foi verificado devido ao fato de que mesmo havendo PCD's com valores altos de precipitação mensal, como a localizada em Piquete, outras apresentaram valores próximos e muitas vezes menores que a precipitação mensal 
observada no pluviômetro. É evidente também, que as menores diferenças entre precipitação mensal interpolada e observada são para os meses considerados secos (abril-outubro) (Figura 4 (a)).

Na Figura 5 (b) encontra-se a precipitação diária interpolada das PCD's e do pluviômetro, no mesmo período (junho/2010 até julho/2011). Também foi verificado que na maioria dos dias a precipitação interpolada foi subestimada (em $65 \%$ dos dias). Devido à variabilidade espacial da precipitação, muitas vezes por se tratar de precipitação local, os totais diários e a distribuição da precipitação foram influenciados pelos valores diários extremos (máximos e mínimos) nas diferentes localidades, contribuindo desta forma para que os valores diários de precipitação interpolados se distanciassem dos valores observados na microbacia.

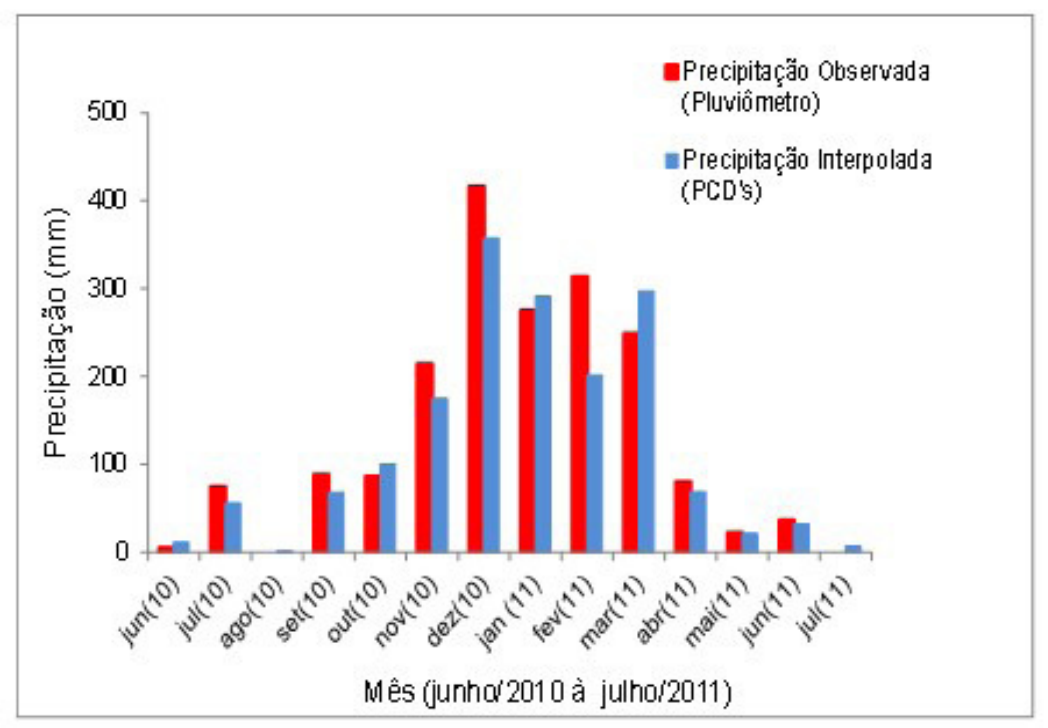

(a)

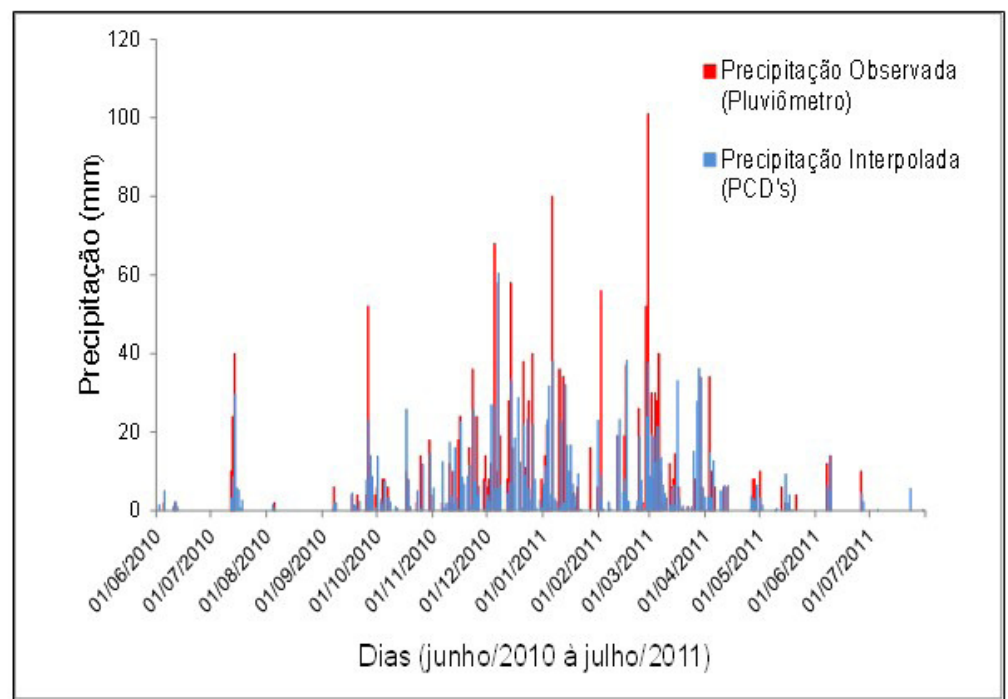

(b)

Figura 5- precipitação mensal (a) e diária (b), interpolada e observada das PCD's e do pluviômetro.

Na Figura 6 (a), é apresentado o ajuste linear (Equação de regressão) da precipitação mensal observada do pluviômetro em função da precipitação mensal estimada (interpolada), obtendo-se um bom ajuste com $R^{2}=92,2 \%$. Na Figura 6 (b), também é apresentado 0 ajuste linear (Equação de regressão) da precipitação diária observada do pluviômetro em função da precipitação diária estimada (interpolada), obtendo-se um ajuste pior, com $\mathrm{R}^{2}=37,9 \%$, o que era de se esperar devido à subestimação da precipitação diária interpolada.
Geografia Ensino \& Pesquisa, v. 16, n. 3 p. 179-188, set./dez. 2012

Alvarenga, L. A.; Martins, M. P. P.; Cuartas, L. A.; Viana, D. R. Andrade, A. 


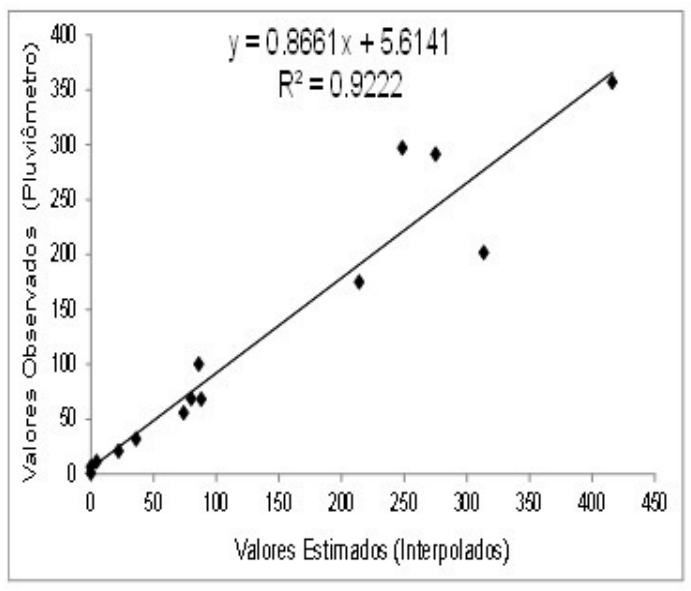

(a)

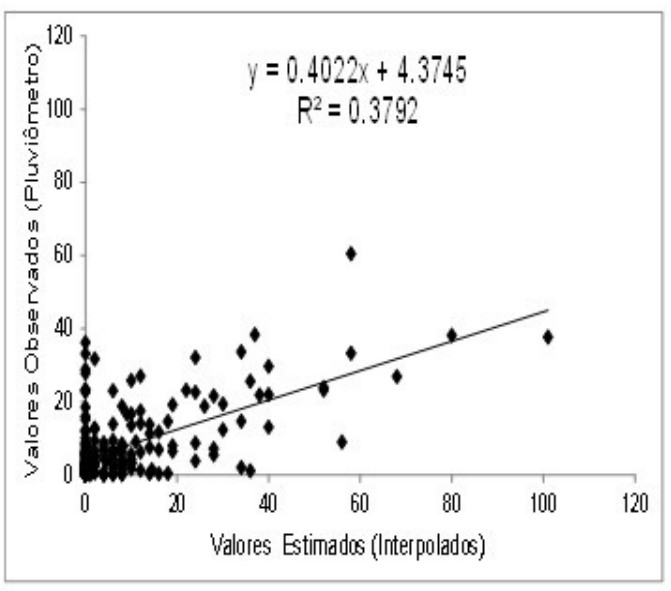

(b)

Figura 6- Equação de regressão linear para as precipitações mensais (a) e diárias (b) do pluviômetro (precipitação observada) em função das precipitações mensais e diárias das PCD's (precipitação interpolada).

$\mathrm{Na}$ Tabela 1 (a) com a análise de variância da regressão (valor do teste F), pode-se concluir que o modelo de regressão linear obtido para precipitação mensal, foi significativo aos níveis de 1 e $5 \%$ de probabilidade. Pode-se observar que $92,2 \%$ das variações dos valores de precipitação observada podem ser explicadas pelas variações nos valores de precipitação mensal interpolada. Desta forma, a interpolação utilizando o método da Krigagem pode ser utilizada para obter valores mensais de precipitação.

Já na Tabela 1 (b) observa-se que somente $37,9 \%$ das variações dos valores de precipitação observada podem ser explicadas pelas variações nos valores de precipitação diária interpolada. Sendo assim, a obtenção da precipitação diária pelo método da Krigagem fica a critério de cada estudo, devido às necessidades e peculiaridades de cada um destes.

Tabela 1- Análise de variância do modelo de regressão linear entre precipitação mensal (a) e diária (b), observada e interpolada.

\begin{tabular}{|c|c|c|c|c|c|c|}
\hline \multicolumn{7}{|c|}{ (a) } \\
\hline FV & GL & SQ & QM & $F_{c}$ & $F_{t}$ & $F_{t}$ \\
\hline Regressão & 1 & 218455,0 & 218455,0 & $142,3^{* *}$ & 9,3 & 4,7 \\
\hline Erro & 12 & 18422,0 & 1535,0 & & & \\
\hline \multicolumn{7}{|c|}{ (b) } \\
\hline FV
\end{tabular}

Geografia Ensino \& Pesquisa, v. 16, n.3 p. 179-188, set./dez. 2012

Espacialização da precipitação na escala mensal e diária em uma microbacia localizada no Vale do Paraíba do Sul, São Paulo
Os autores Silans et al. (2009) afirmam que, em bacias hidrográficas médias e grandes, a importância da variabilidade espacial da precipitação sobre a geração do escoamento superficial é reconhecida. Já, em pequenas bacias, ou em sub-bacias, geralmente se considera uma precipitação uniforme estimada a partir de um único posto pluviométrico. No entanto, os seus estudos mostram que em caso de precipitações convectivas, mesmo em pequenas bacias, a variabilidade espacial da precipitação deve ser levada em consideração e deve-se utilizar um método adequado de interpolação. Desta forma, nesse estudo a variação dos dados diários de precipitação interpolados em relação aos observados também pode estar relacionada a precipitações convectivas.

Rosa e Satyamurty (2003) também destacam que a atividade convectiva sobre o Vale do Paraíba apresenta padrões que são claramente influenciados pelo relevo local e pelo contraste terra e mar (brisa marítima). A área de atividade convectiva entre Guaratinguetá (onde se encontra parte do ribeirão dos Macacos) e Pindamonhangaba possui este padrão dominante e o mais importante em todo o Vale. 


\section{Conclusões}

O método de interpolação da precipitação utilizando a técnica da Krigagem pode ser utilizado na obtenção de precipitação mensal. No caso da obtenção de precipitação diária, este método apresentou um menor ajuste $\left(R^{2}=37,9 \%\right)$, quando comparado com o ajuste obtido da interpolação mensal $\left(R^{2}=92,2 \%\right)$.

É importante ressaltar o quanto a interpolação na escala mensal é mais representativa do que na escala diária. A precipitação mensal é a somatória dos valores diários de precipitação no mês, desta forma em determinadas localidades que não ocorreu precipitação, pode ter ocorrido uma compensação devido à precipitação diária de dias diferentes. Isto pode explicar o fato dos valores mensais interpolados (precipitação-PCD's) serem mais aproximados dos valores observados (precipitação-pluviômetro) quando comparado aos valores diários interpolados.

Em meses mais secos (abril-outubro) quando comparado aos meses mais úmidos (novembromarço) se tem os melhores resultados da precipitação obtida pelo método da Krigagem. Os resultados menos aproximados da precipitação nos meses mais úmidos podem estar relacionados ao relatado por Dereczynski et al., (2009). Esses autores destacam que no verão e na primavera, os eventos de precipitação podem estar associados ao caráter convectivo da precipitação, influenciada provavelmente pelo maior aquecimento local em regiões que sofrem fortes impactos devido às ações antrópicas.

\section{Agradecimentos}

Agradecemos ao CNPq pela bolsa de mestrado concedida, ao CPTEC/INPE pela disponibilização dos dados de precipitação das PCD`s, ao Instituto Oikos de Agrecologia pela disponibilização dos dados de precipitação do pluviômetro localizado na microbacia do Ribeirão dos Macacos.

\section{Referências}

BARBOSA, J. P. M. Utilização de métodos de interpolação para análise e espacialização de dados climáticos: o SIG como ferramenta. Revista Caminhos de Geografia, v. 9, n. 17, p. 85-96, 2006.

CAMARGO, E.; DRUCK, S.; CÂMARA, G. Análise de superfícies por geoestatística linear. In: DRUCK, S.; CARVALHO, M.S.; CÂMARA, G.; MONTEIRO, A.V.M. Análise espacial de dados geográficos. Brasília, EMBRAPA, 2004. Cap. 3, p. 13-37.

CARVALHO, J. R. P. de.; ASSAD, E.D. Análise espacial da precipitação pluviométrica no Estado de São Paulo: comparação de métodos de interpolação. Revista Engenharia Agrícola, v. 25, n. 2, p. 377-384, 2005.

CONSENTINO, P. Resumo da teoria, 875 problemas resolvidos, 619 problemas propostos. Estatística. São Paulo: McGraw-Hill do Brasil, 1977. p. 1-569.

DANFA, S.; SILVA, A. M.; MELLO, C. R. de ; COELHO, G. ; VIOLA, M. R; AVILA, L. F. Distribuição espacial de valores prováveis de precipitação pluvial para períodos quinzenais, em Guiné-Bissau.

Revista Brasileira de Engenharia Agrícola e Ambiental, v. 15, p. 67-74, 2011.

DERECZYNSKI, C. P.; OLIVEIRA, J. S.; MACHADO, C.O. Climatologia da precipitação no município do Rio de Janeiro. Revista Brasileira de Meteorologia, v. 24, n. 1, p. 24-38, 2009.

Geografia Ensino \& Pesquisa, v. 16, n.3 p. 179-188, set./dez. 2012

Alvarenga, L. A.; Martins, M. P. P.; Cuartas, L. A.; Viana, D. R. Andrade, A. 
DUFEK, A. S.; AMBRIZZI, T. Precipitation variability in São Paulo State, Brazil. Theoretical and Applied Climatology, v. 93, p. 167-178, 2008.

FISCH, G. Caracterização climática e balanço hídrico de Taubaté (SP). Revista Biociências, v. 1, n. 1, p. 81-90, 1995.

GOLDEN SOFTWARE. Surfer version 8 - surface mapping system. Golden: Golden Software, Inc., 2002.

LIMA, K. C.; SATYAMURTY, P.; FERNÁNDEZ, J. P. R. Large-scale atmospheric conditions associated with heavy rainfall episodes in southeast Brasil. Theoretical and Applied Climatology, v. 101, n. 1-2, p. 121-135, 2010.

MENEZES, M. D.; JUNQUEIRA JUNIOR, J. A.; MELLO, C. R.; SILVA, A. M.; CURI, N.; MARQUES, J. J. Dinâmica hidrológica de duas nascentes, associada ao uso do solo, características pedológicas e atributos físico-hídricos na sub-bacia hidrográfica do Ribeirão Lavrinha - Serra da Mantiqueira (MG). Scientia Forestalis, v. 37, n. 82, p. 175-184, 2009.

MELLO, C.R.; LIMA, J.M.; SILVA, A.M.; MELLO, J.M.; OLIVEIRA, M.S. Krigagem e inverso do quadrado da distância para interpolação dos parâmetros da equação de chuvas intensas. Revista Brasileira de Ciência do Solo, n. 27, p. 925-933, 2003.

ROSA, M. B.; PRAKKI S. Um estudo da atividade convectiva no verão sobre o vale do paraíba através do radar banda-S de São José dos Campos. Revista Brasileira de Meteorologia, v. 18, n. 2, p. 195-206, 2003.

SANTOS, G. V.; Dias, H. C. T.; Silva, A. P. S.; Macedo, M. N. C. Análise hidrológica e sócioambiental da Bacia Hidrográfica do Córrego Romão dos Reis, Viçosa - MG. Revista Árvore, v. 31, n. 5, p. 931-940, 2007.

SILANS, A. M. B. P.; ALMEIDA, C. N.; PORTO, R. Q. Impacto da incerteza na representatividade da repartição espacial da precipitação sobre os hidrogramas e as curvas de permanência obtidos de um modelo chuva-vazão distribuído. Revista Brasileira de Recursos Hídricos, v. 14, n. 2, p. 59-71, 2009.

VIANA, D. R. Comportamento espaço-temporal da precipitação na Região Sul do Brasil utilizando dados TRMM e SRTM. 2009. 162 p. (INPE-15738-TDI/1484). Dissertação (Mestrado em Sensoriamento Remoto) - Instituto Nacional de Pesquisas Espaciais, São José dos Campos, 2009.

\section{Correspondência:}

Livia Alves Alvarenga - Universidade Federal de Lavras. Campus Histórico da UFLA. Centro. 37200-000 - Lavras, MG - Brasil

E-mail: liviaalvesalvarenga@yahoo.com.br

Geografia Ensino \& Pesquisa, v. 16, n.3 p. 179-188, set./dez. 2012

Espacialização da precipitação na escala mensal e diária em uma microbacia localizada no Vale do Paraíba do Sul, São Paulo
Recebido em 12 de setembro de 2012.

Revisado pelo autor em 20 de novembro de 2012.

Aceito para publicação em 17 de dezembro de 2012. 